\title{
OJED
}

ISSN: 2162-3104 Print/ ISSN: 2166-3750 Online

Volume 9, Issue 2 (2019), pp. 661-681

doi: $10.32674 /$ jis.v9i2.641

(C) Journal of International Students

https://ojed.org/jis/

\section{Expanding Meaningfulness: Perceptions and Strategy Use of Chinese International Graduate Students in Disciplinary Reading}

\author{
Yang Wang \\ University of South Carolina, USA
}

\begin{abstract}
This qualitative case study explored two Chinese international graduate students' beliefs about their reading and reading processes. The researcher interviewed the participants, asked them to read aloud, analyzed their reading using miscue analysis, and then discussed their reading with them using retrospective miscue analysis (RMA). The researcher found that readers' beliefs were not static and text difficulty influenced the students' reading beliefs and strategy use. Through RMA, both students became aware of their respective reading processes and they both became more confident as readers. This study suggests that RMA is an effective tool for English-as-anadditional language graduate students, as it helps in the construction of meaning and the improvement of disciplinary literacy skills.
\end{abstract}

Keywords: disciplinary reading, international graduate students, qualitative case study, reading belief, reading process, retrospective miscue analysis

\section{INTRODUCTION}

In 2015-2016, there were more than one million international students enrolled in post-secondary institutions in the United States; more than $30 \%$ of 
these students were from China (Institute of International Education, 2016). China is the number one country of origin for international students and scholars in the United States (Ma \& Wang, 2014). International students' language proficiency affects their adjustment to academic success and social life (Andrade, 2009). Many Chinese international students struggle with English language skills and find it challenging to learn content knowledge from textbooks written in English (Su \& Harrison, 2016; Wang \& Zuo, 2014). Their general reading strategies are not always sufficient, as English texts are often discipline-specific. For example, reading a social studies text and a science text require different sets of reading strategies.

This case study was designed to explore the effect of retrospective miscue analysis upon two Chinese international graduate students' understandings of their own reading processes. It uncovered their reading strategies in English when they read disciplinary texts-the professional books and articles in their fields. The purpose of this study was to explore how Chinese international graduate students' used reading strategies in their disciplines through retrospective miscue analysis and to provide implications for instructors and faculty who work with international students who speak English as a second language. The research questions were:

- What are the Chinese graduate students' perceptions of themselves as readers?

- Based on retrospective miscue analysis, how do they read in their disciplines?

\section{THEORETICAL FRAMEWORK AND LITERATURE REVIEW}

\section{What is Reading?}

Language is first social then psychological (Vygotsky, 1978). Reading is a social process in which the readers make sense of texts from the information on the page and ideas and thoughts evoked by the texts (Schoenbach, Greenleaf \& Murphy, 2012). Reading is a cognitive process that is a problemsolving operation in one's brain to achieve some goal (Bernhardt, 1991). Reading is using multimodal systems to create and construct meaning in a sociocultural context, and readers negotiate their transactions from a developmental perspective (Kucer, 2014; Rosenblatt, 1978). Reading is "a psycholinguistic guessing game" (K. Goodman, 1976, p. 46). To construct meaning, readers use three linguistic cueing systems; graphophonic, 
syntactic, and semantic and three pragmatic systems; context of situation, background knowledge, and culture (Moore \& Gilles, 2005).

To understand challenging texts, readers are "mentally engaged, motivated to read and to learn, persistent in the face of challenge, socially active around reading tasks, [and] strategic in monitoring the interactive process that assists comprehension" (Schoenbach et al., 2012, p. 21). Reading disciplinary texts requires both language knowledge and disciplinary knowledge and close reading (Fang \& Pace, 2013). Close reading often involves high-quality texts, profound questions, rereading, and discussion. From this sociopsycholinguistic perspective, content-area literacy is being able to read and write for acquiring new content in the disciplines (McKenna $\&$ Robinson, 2014). This ability includes general literacy skills and strategies, prior knowledge of content, and disciplinary-specific skills and strategies.

\section{What is Reading in a Second Language?}

Learning to read in a second language is a complex process that is influenced by the learners' first language and other sociopsycholinguistic and cognitive factors. First language reading, second language proficiency and decoding, educational background, and educational goals all contribute to reading comprehension as well as influence literacy development (Koda, 2007). This means English learners' first language, their English language proficiency, English reading strategies, content area knowledge and learning goals all affect their content area literacy. Language learning is integrated with English learners' content learning (Snow \& Brinton, 1988).

In second language reading, the text does not only include linguistic elements, but also contains its pragmatic nature, intentionality, content, and topic. All those elements affect the reading process and make readers changeable entities. Additionally, the reader's knowledge consisting of locallevel knowledge, domain-specific knowledge, and culture-specific knowledge influences the reading process (Bernhardt, 1991). Furthermore, advanced second language learners need to learn the academic cultures in order to read in their academic fields (Bernhardt, 2011).

Second language readers transfer across languages, and their first language competence can transfer and affect second language development (Koda, 2007). To help non-native speakers learn to read effectively and efficiently in a new language, many scholars have argued for culturally responsive teaching. Fenner and Snyder (2017) argued that culturally responsive teaching is assets-based: a) Students should be the center of 
learning, b) their first language, and home and cultural backgrounds should be valued, c) teachers should support their students as well as challenge them.

\section{What is Retrospective Miscue Analysis?}

A miscue is a difference between the text and what the reader creates (Y. Goodman, Watson \& Burke, 2005). For example, a reader reads a short time period as a short term period and mindset as mindest. The former miscue, term may not change the text meaning; the latter miscue, mindest may change the meaning. Readers would never be utterly proficient with no errors (Bernhardt, 1991). Miscue analysis is an assessment tool to explore readers' cue use (Y. Goodman et al., 2005) and Retrospective miscue analysis (RMA) is an assessment and instructional tool that helps readers revalue themselves as they confer about their reading processes with teachers or researchers (Y. Goodman, 1996; Y. Goodman, Martens \& Flurkey, 2014; Moore \& Gilles, 2005). Metacognition is thinking about thinking; metacognitive conversations like RMA helps readers become aware of their own thinking and problem-solving (Schoenbach et al., 2012).

In an RMA procedure, usually one teacher or researcher works with one reader. The teacher or researcher would:

- Select comparatively challenging reading pieces based on the reader's interests and/or encourage the reader to bring in some reading materials.

- Invite the reader to read aloud the text or a selection of what the reader brought as if the reader were reading by oneself. (Approximately 500 words.)

- Quickly jot down some miscues on paper while listening to the reader's reading - preferably a few high-quality miscues that did not change the meaning of the text and a few low-quality miscues that changed the meaning of the text.

- Ask the reader to retell what the reader just read. Ask aided questions in the retelling.

- Confer with the reader about the high-quality miscues first and then about the low-quality miscues. Help the reader name the reading beliefs, notice the strengths and needs, and teach new strategies.

- Repeat for as many sessions as needed or weekly or monthly sessions. 


\section{Previous Studies}

Previous studies (Gilles \& Peters, 2011; Y. Goodman, 1996; Marek, 1987; Martens \& Doyle, 2011; Moore \& Gilles, 2005; Paulson \& MasonEgan, 2007) found that retrospective conversations of RMA with teachers and researchers helped readers build their confidence in reading, learn about reading strategies, value their reading, gain agency, and become lifelong readers. Previous studies with English learners (Almazroui, 2015; Kim, 2010; Moteallemi, 2010; Wang, 2014; Wang \& Gilles, 2017; Wang \& Zheng, 2019; Wurr, Theurer \& Kim, 2009) found that RMA was a powerful instructional strategy for students who spoke Korean, Spanish, Arabian, and Chinese Mandarin.

Previous studies have explored the specific strategies that learners use to read in their disciplinary fields (Schoenbach et al., 2012; Shanahan, 2013; C. Shanahan \& Shanahan, 2014; T. Shanahan \& Shanahan, 2008). Some researchers have examined disciplinary literacy of English language learners. Protacio and Jang (2016) studied English language teachers' beliefs and found that accessible texts, English learners' self-concept, and reading purpose influenced English learners' reading motivation. O'Brien and Leighton (2015) determined that complex read-aloud text contributed to first-grade English language learners' academic language and content knowledge achievement. And Na, Schaller, and Jee, (2015), who studied Korean high school English learners, found that students responded to emotional texts to a greater degree than to neutral texts when engaged with culturally situated emotions.

Many studies examined college students' academic reading in their second language. Li and Munby (1995) studied two Chinese graduate students' academic reading and found metacognitive strategies are crucial for reading in a second language for academic purposes. Huang (2006) surveyed 212 college English as foreign language learners and found teachers' help, marked-up texts, and instruction of reading skills motivated students to learn for academic purposes. Chou (2013) compared English as a foreign language students' reading for general and academic purposes and found they used similar strategies but to different degrees.

Although think-aloud studies have been conducted to explore second language reading (Bernhardt, 2011), RMA has not been used widely with adult English learners or international students in the United States. This instructional and assessment tool requires more time and efforts for teachers or instructors to work closely with the learners individually. None of these studies used retrospective miscue analysis to address the reading perceptions 
and processes of international students' disciplinary literacy. As an English learner, researcher, and teacher educator, I understand the challenges of learning disciplinary knowledge in English as an additional language and the importance of providing scaffolding and support for students in higher education. I wanted to understand more about what the Chinese international students' reading perceptions and how they read in their disciplinary area.

\section{RESEARCH METHOD}

This qualitative case study describes the adult English learners' reading process in depth within the higher-education context. This study copes with many variables that affect reading and relies on multiple sources of data.

\section{Participants}

I recruited the participants through in-person contact following the criteria. Participants must: have had K-12 education and bachelor's degrees in Mainland China, speak Chinese Mandarin as their first language, have learned English during middle school and have proficient interpersonal communication skills. I selected two female Chinese international graduate students, Jiamei and Wenwen (all names are pseudonyms) from a large university in the southeastern United States. They struggled with academic language proficiency in reading and writing in English. This may be because English teaching at middle and high school and non-English major undergraduate programs in China are full of practice and drill, and many students learn just to pass the tests. Students learn new words, sentence structures, translation between the two languages, and background knowledge about western culture. They read and write to learn the language and not for content area knowledge. Their scores of Test of English as a Foreign Language and Graduate Record Examinations are about the average among international students. When the study began, Jiamei and Wenwen had been in the United States for three months and were adjusting to academic learning in English and their new cultural context.

Jiamei obtained her bachelor's degree in Accounting in Mainland China and then worked part-time as a basketball coach until she came to the United States for her master's degree program in Sports Business and Entertainment. Wenwen obtained a master's degree in English and Chinese Translation and taught English language in a private high school for a year in China before coming to the United States. She was waiting to start her doctoral program in Education at the time she participated in the study. The two participants' 
backgrounds represent many international students studying in the United States. They received their K-12 education and obtained their bachelor degrees in China. They had lived in the states less than a year at the time of this study. English was their second language, and they struggled with the intense reading at the graduate school. The two participants are the bounded case in this study.

\section{Procedure}

The participants and I met individually, for five bi-weekly sessions during the fall semester; each meeting lasted approximately one hour. We met at the campus library and the study rooms. I collected multiple sources of data throughout the study, which are presented below.

In the introductory meeting, using the Burke Reading Interview protocol (Y. Goodman et al., 2005), I talked with each participant about her perceptions of reading and the strategies each used when reading texts written in English. We chatted informally as I encouraged Jiamei and Wenwen to expand upon their responses. I asked my questions in English and, when requested to do so, I translated them into Chinese. Both participants responded in Chinese. I audio-recorded and transcribed the interviews for later analysis.

For interviews two through five, I asked Jiamei and Wenwen to choose English texts from their respective academic areas due to the purpose of this study. I told them they could browse the texts regarding the title, content, and length, as long as:

- The content related to their study areas.

- The text included material such as professional journal articles, or chapters in their textbooks.

- Each piece was at least 500 words long.

- They waited to read the texts until we were together.

Each participant selected one English text for each meeting, using these criteria, and sent the texts to me before we met, so I could make copies for miscue marking and note taking.

Jiamei selected:

- one chapter about managing diversity from her textbook,

- an article about sports management,

- a law case from her course, and 
- the preface of a bestselling book about the psychology of success. Wenwen selected:

- the preface of a book about second language learning,

- an article about plagiarism in Japanese universities,

- an article about plagiarism and patchwriting in second language writing, and

- a book chapter about sociocultural theory and second language learning.

At each meeting, Jiamei or Wenwen read aloud their chosen texts and then retold what they read following the miscue analysis procedure (Y. Goodman et al., 2005). Reading aloud is required for this procedure so the researcher or teacher can mark and use the miscues to investigate the reading process. My personal experience of being a bilingual speaker and working with Chinese English learners for years allow me to differentiate the participants' accent and dialects caused by their first language. I also understand that reading aloud may complicate some English learners' comprehension; however, this is the only way I could adopt to look into their reading process without the assistance of technology.

The participants read articles and chapters on their tablets except for two instances, when each brought in the preface of a hard copy book. When the chosen text was too long, we decided collaboratively about which section to read aloud. Usually, we chose a relatively complete part such as the introduction, literature review, or findings. For example, when Wenwen read a professional article, she read the introduction silently and then read the complete literature review aloud. As the participants read aloud, I sat by them, listened, marked their miscues, and took notes on my hard copies that I had prepared in advance.

After the participants read aloud, I invited them to retell everything that they remembered. Both participants responded in Chinese. I asked some aided questions that encouraged them to recall and share more. For instance, I asked, "You mentioned [X]. Tell me more." "Why do you think [Y]?" "What connections did you make when you read [Z]?" I audio-recorded the reading and retelling. I also took notes about the retelling in the margins and in the empty spaces on my copies.

After the reading and retelling, I quickly selected a few miscues to talk about (Moore \& Gilles, 2005). When there were only a few miscues from a piece, we discussed them all. I selected the miscues that did not change the meaning of the texts and talked about them first. Then we talked about miscues that changed the meaning of the texts. I asked questions for each 
miscue like, "Did it sound like language?" "Did it make sense?" "Did it change the meaning of the text?" "Why did you make this miscue?" Additionally, I modified those questions and added open-ended questions to allow the participants to talk about anything that they were willing to share about their reading beliefs, processes, and comprehension. Due to the purpose of this study, we did not talk about the phonic variations that they made because of accent or dialects. I audio-recorded and transcribed all the RMA sessions.

I kept field notes after each meeting with the participants. In the notes, I described the context and noted what I observed initially regarding the students' reading beliefs, the reading process, strengths, struggles, and comprehension. The field notes were also used for data analysis.

\section{Analysis}

This study borrowed the case study protocol and developed case study database (Yin, 2017). Multiple sources of evidence introduced in the section above were collected for analysis. Relying on my theoretical propositions and my positionality, I open coded all the data of the interviews, the miscue analysis, the retelling notes, RMA transcriptions, and the field notes. I worked from the "ground up" (Yin, 2017, p. 136) and used Glasser and Strauss' (1967) constant comparative method to analyze the data. Initial codes included meaning-making, accuracy, purpose, vocabulary, paragraph organization, sentence structure, background knowledge, use of context, words omitted, words looked up, and self-reflecting. The themes of reading beliefs, text feature, reading strategies, and language use emerged from the data.

I did pattern matching and asked for the participants' responses and if they had any questions. The findings were shared with the participants for member checking. Based on the case description, I labeled Jiamei a metacognitive reader and Wenwen, a reading deliverer.

\section{JIAMEI, A METACOGNITIVE READER}

Jiamei had different standards evaluating herself as a reader in her first and second language. She acknowledged, "As a Chinese [native speaker], my reading is not good. However, as a second language learner, compared with many other learners, I am okay [reading in English]." Jiamei found the many new English words challenging when reading in her discipline. She was metacognitive about her reading process when she read for an academic 
purpose. She applied multiple reading strategies and was aware of when to use them in her reading.

Jiamei thought that reading in English was about learning things. Her purposes for reading influenced her reading beliefs. She predominantly read academic materials and rarely read in English for pleasure. Jiamei started her retelling by stating the main idea, and she used her prior knowledge to understand what she was reading. When she read assigned law cases, she knew that her professor would ask students to share their opinions in class. Because of this, Jiamei tried not only to understand the text, but also to form an opinion about what she read. Jiamei wanted to go back and work in China after she received her master's degree. Her career goal made her connect her academic readings to related situations in China.

Jiamei told me that when she read, she translated the texts into Chinese. She said that she used Google translate when she read by herself. She opened the Google translate webpage on her computer monitor screen and set her tablet beside the screen. When she read something that she did not know, she typed it into Google translate. Even though she knew the website did not always offer accurate translations, she was able to understand some major concepts. She then translated these concepts into Chinese. When she was not able to understand everything in Chinese, she reread the texts, translating into Chinese, while embedding English words. She said that she understood the terms and jargon in English better when there was not an appropriate one-onone translation in Chinese.

Jiamei was familiar with the text features because she selected the texts by herself and had been reading similar texts for her coursework. She noticed the text features of the sentence structure, endnotes, and the organizations of paragraphs, sentences, and subsections. Knowing these text features helped her to read efficiently and effectively. She was aware that some words used in the law cases and other content materials sometimes had meanings that differed from those used in daily life. For example, she read Tarkanian then filed suit against $U N L V$, and mentioned those words of file and suit have different meanings in different contexts.

Jiamei was efficiently and effectively able to use multiple strategies to read for meaning. She murmured or silently reread long sentences. Jiamei explained that she needed to understand the complete sentence, and then translate it into Chinese. Many times, she scrolled up and down across paragraphs on her tablet. When she read the book chapter, she referred back to the objectives listed in the beginning. She loved reading on her tablet because there was no page break in the tablet application that she used, and this helped with her flow of reading. 
When Jiamei came to parts of the text she considered unimportant, such as words in parentheses and introductory sections, she was comfortable with skipping chunks of texts. When she met new names for people and places, she replaced these words with their initial letters. For instance, she read Jerry Tarkanian as Jerry $T$.

Jiamei constantly looked up new words during her oral reading, retelling, and our discussion. She either looked in the drop-down dictionary in the book or typed in an online dictionary. We conferred about this strategy in one RMA session:

Researcher: When you meet something that you don't know, would you hold and decide if you need to look them up after you finish reading that paragraph?

Jiamei: No, I can't. I would forget. If I don't understand, I may forget the previous sentence when I keep reading.

Researcher: So you think you need to read every sentence to understand?

Jiamei: Not necessarily. But I am afraid that if I don't understand one sentence it may bother my understanding the entire text.

Researcher: How often would you look them [new words] up?

Jiamei: Not everyone. It's automatic in my iPad. [She showed me the drop-down dictionary.] I just need to know the general meaning and then put it into the context.

Researcher: Could you look them up after you finish reading this paragraph?

Jiamei: No, I really can't. I will forget after three seconds.

Researcher: Do you think [understanding] this short paragraph is very important in the text?

Jiamei: I divide a long article into small sections. Each small section is the only one. So I have to understand [this small section].

Researcher: Would you underline them first and then see if you can understand the main idea?

Jiamei: It bothers me if I don't know this word.

Even though Jiamei valued reading for meaning, made connections with real life, and reflected independently, she needed to know all the new words 
in the text to be comfortable and confident about understanding the meaning. Jiamei was unaware of the importance of contextual clues in the text and seemed to believe reading is word decoding.

\section{WENWEN, A READING DELIVERER}

Wenwen believed that "Reading is learning. I read to learn something with purposes. Once my language skills are improved, I can read for pleasure." She told me that when she read aloud, she always imagined there was an audience in front of her. She wanted her audience to receive accurate information so she delivered the content for them.

Wenwen made a few miscues when she read. She retold many details from what she read; however, she had a hard time connecting the details to get the main idea. After the first RMA session, Wenwen performed two rounds of retelling. During the first round, she retold every detail she remembered. She listed the details in words, phrases, and short sentences, which made her retelling very choppy. In the second round, she linked the details together and organized them into the main idea with supporting evidence. Her retelling flowed better, and she was better able to understand the text.

Wenwen noticed text features and relied upon them to navigate the text. For example, she paid attention to the organization of subsections, used context to predict meaning, reflected on her reading and paused to think, used the graphic and phonic information, and looked at a word's prefix and root to help predict the meaning. She also broke words into parts. For example, she separated the syllables in backhoe and read it in context to try to figure out what it meant.

Wenwen adjusted her reading strategies. For example, the second text she read was a professional article with many in-text citations. At first, Wenwen read aloud all the text in the parentheses: "carry the same negative connotations left parenthesis Bloch, 2001; Dryden, 1999; Scollon, 1995 right parenthesis" [emphasis added]. Then, Wenwen added words before in-text citations to make her reading flow better. For example, when the text read, Taking a contradictory view to this position, some (Bailey, 2002; Baumann, 1996)... she read, "Taking a contrary view to this position, some, for example, Bailey, 2002 and Baumann, 1996 ..." [emphasis added]. Similarly, when the text read, Baumann (1996) notes that... she read, "Baumann at 1996 notes that ..." [emphasis added]. During the third RMA, Wenwen omitted all the in-text references. She explained that she initially 
wanted to make sure her audience received all the information, and then she realized that it was okay to omit information in the text.

Wenwen sometimes substituted words that I thought resulted in meaning loss; however, she thought her substitution made sense in her language. For example, in the first line of this sentence, she substituted the word is for in and we had the following discussion: ... plagiarism in technical writing begins with the simple assertion that one obvious cause [of increased plagiarism] is the influx of foreign students into Engineering fields ... [emphasis added].

Researcher: Do you think it [substituting is for in] changed the meaning of the text?

Wenwen: No, I don't think so. I think it may not be right according to [English] grammar, but it didn't change the meaning. Well, if I look at the grammar now, it may change the meaning a little bit as one is plagiarism in technical writing, the other is plagiarism is technical writing.

Researcher: Should you change it?

Wenwen: But I think, I did something like mixing the orders of words in a sentence in Chinese and I would still be able to understand the meaning. For example, a sentence 我今天吃饭了 I today ate, if we put it as 今 天吃饭我了 today ate I. We can still understand. So I wonder if [English] native speakers would be able to understand when they hear it [Wenwen's miscue of is].

When Wenwen translated the initial sentence into Chinese for understanding, it made sense to her. She used the language cueing systems across the two languages to make meaning.

\section{CROSS-CASE FINDINGS}

There were similarities and differences between Wenwen and Jiamei relative to their reading beliefs and strategies, the way they navigated difficult texts, and how they switched between languages. Both participants ultimately increased their confidence in themselves as readers and became more metacognitively aware. 


\section{Reading Beliefs}

Both participants valued recognizing words and making sense of the text. They both focused on learning new information from what they read. Jiamei believed that she read for meaning, not word-by-word and that was consistent with her retelling and our conversations. However, when she encountered a new word, she took actions to understand it. Wenwen initially believed that she needed to decode the words for meaning and she began to value meaning over accuracy.

\section{Reading Strategies}

Wenwen and Jiamei used a variety of reading strategies. In the earlier sessions, Jiamei looked up all the new words. In the later sessions, using context, she guessed at some of the new words. Similarly, Wenwen adjusted her strategies. For instance, she played with the texts in the parenthesis until she was sure she understood the text. She often used independent strategies, such as consistently using the context, looking at the root and prefix of a new word, and pausing and reflecting.

\section{Navigating Difficult Text}

When the text became difficult, both participants slowed down and reread. Jiamei often reread sentence by sentence and looked up new words when the text was complex. When Jiamei became familiar with the text features and had sufficient background and prior knowledge, she was comfortable with skipping words, clauses, and sentences, as they did not influence her meaning-making. Wenwen first focused on the details that she remembered and was subsequently able to connect the details to main ideas for understanding challenging texts.

\section{Switching Languages and Translating}

Wenwen and Jiamei switched between two languages for meaningmaking. They both retold and talked about their reading in Chinese. They reported that they translated into Chinese to understand and that they sometimes kept terms and jargon in English. When Jiamei and Wenwen translated into Chinese, they used Chinese syntax to restructure the sentence. Although some miscues were not syntactically acceptable and changed the meaning, they were still able to reconstruct the meaning in Chinese. 


\section{Building Confidence and Becoming Metacognitive}

Through RMA, Wenwen and Jiamei read closely. They read, retold, reread, answered and asked questions, discussed their reading, and decoded words and sentences. They became aware of their reading processes and increased their confidence as readers. For instance, Wenwen was more comfortable omitting the words in parenthesis when she read. Jiamei became confident guessing the meaning of new words. Both participants started observing and noticing their own reading strategies and started to feel successful as readers.

\section{DISCUSSION AND CONCLUSIONS}

Reading is a complex process, and disciplinary reading is particularly complex. Through RMA sessions, the two Chinese international graduate students shared their reading beliefs and processes. This case study found that the two participants' reading beliefs were not static. Their beliefs changed based on their purposes of academic reading. Bernhardt (1991) discussed that second language readers are changeable and their reading process is affected by many factors. In this study, text features and difficulty influenced the participants' reading strategy use. They used all language cueing systems to create meaning no matter what disciplines (K. Goodman, 1976; Moore \& Gilles, 2005). They carefully and purposefully reread the text. They chose efficient and effective general reading strategies and used their prior knowledge of content when they read. Becoming familiar with the content area text features helped them navigate the texts. Realizing their reading strategy use contributed to them becoming more confident and successful with their academic reading.

The Chinese international graduate students approached English texts in the language that was effortlessly accessible to them. They translated from English to Chinese and switched between two languages. They usually relied on Chinese to carry the meaning and included some terms in English to facilitate their understanding. Along with the previous theories and studies (Bernhardt, 1991, 2011; Koda, 2007; Snow \& Brinton, 1988), this study also found that the international students' first language, their English language proficiency, their English reading strategies, content area knowledge and their learning goals all affect their academic reading. Meaning exists in the transaction between the reader and the text (Rosenblatt, 1978) no matter what languages the readers read and what languages they utilize to understand. 
International students decided on their strategies based on their academic goals, reading efficiency and effectiveness.

The retrospective conversations about the readers' miscues allowed the international students to reread, think of more in-depth questions, and discuss the text. Conferring about their miscues and examining why they made them helped Wenwen and Jiamei expand meaningfulness in their disciplines. It also gave the participants the opportunity to observe their reading, notice their own thinking, and cultivate metacognition in their academic reading. As they became aware of their strengths and needs in reading, they gained confidence and became more metacognitively aware of themselves as readers. Through the RMA sessions, the two international students valued their academic reading and developed into engaged, strategic and independent readers in their disciplines. When international students become metacognitive about their disciplinary learning, they are more confident when dealing with challenging academic reading and better prepared for their future careers.

\section{IMPLICATIONS}

This study provides insights for course instructors, faculty, English language teachers and learners in exploring readers' meaning construction and improving disciplinary literacy skills. International students who speak English as an additional language may share different beliefs about academic reading in different disciplines. Faculty, instructors, and English language teachers can help students discover their own beliefs and academic goals. Reading conversations like RMA allow instructors and teachers to involve students in metacognitive conversations and encourage students to think about their thinking. All instructors can adopt retrospective conversations to value students' reading and help them develop into engaged, strategic, and independent readers in their second language and their disciplines.

The study also suggests that instructors and teachers should value international students' first language and encourage them to use it to make meaning in disciplinary reading. Allowing the international students to confer about their English reading in their first language would value their first language and culture; meanwhile, it would support the students as they take on the challenge of learning disciplinary knowledge in English. Although the instructors and teachers may not be able to speak the students' first language, they can encourage the students to choose an effective way of making meaning and engage the students in interacting with their peers who share the same first language. 


\section{LIMITATIONS AND FUTURE STUDIES}

As a common limitation of a case study, the findings cannot be generalized to a more significant population. I presented two types of readers in this study and other readers may have different types of reading styles. Even the same readers may change their reading styles over time. Future researchers could study more participants and over a longer extended period.

I listened to the participants reading aloud while conducting RMA, instead of marking the miscues after the readings. Although I am familiar with miscue analysis and RMA and have used them frequently with diverse readers, it was challenging to capture every miscue while listening and marking simultaneously. Future researchers could audio record the readings and retellings, then listen to the recordings multiple times and check the miscues. They could also have their markings reviewed. The researchers could design measurement before and after the RMA sessions to evaluate the students' growth as readers. Further research could use technical assistance, for instance, using an eye tracker to record the silent reading process and engage participants in a retrospective interview.

In this case study, I was the sole researcher. Having a co-investigator would help avoid bias in reporting and analyzing data. A common weakness of conducting interviews was the interviewee may want to please the interviewer by giving what the interviewer wants to hear. There might be bias due to the researcher's manipulation of events (Yin, 2017) and it may be difficult to record all the essential events.

This study serves as an example of research on the reading process and academic English reading strategies in different disciplines. It would benefit the researchers who are interested in English language reading and other second language reading and learning in various disciplines. In this study, I worked with two volunteers from two different disciplines. The text features were similar among all the materials that the two participants selected. The strategies they used were general content area reading strategies. Future studies could include more students from a variety of disciplines. For example, readers in computer science, engineering, or medicine may use other disciplinary-specific strategies. Further research could investigate the academic second language reading of readers from various cultural backgrounds different than Chinese. Moreover, it would be helpful to compare and contrast the reading processes of the first language and the second language for academic purposes. 


\section{REFERENCES}

Almazroui, K. (2015). Learning together through Retrospective Miscue Analysis: Salem's case study. Reading Improvement, 52(2), 72-84.

Andrade, M. (2009). The effects of English language proficiency on adjustment to university life. International Multilingual Research Journal, 3, 16-34.

Bernhardt, E. (1991). Reading development in a second language: Theoretical, empirical, and classroom perspectives. Norwood, NJ: Ablex Publishing Corporation.

Bernhardt, E. (2011). Understanding advanced second-language reading. New York, NY: Routledge.

Chou, M. (2013). Strategy use for reading English for general and specific academic purposes in testing and nontesting contexts. Reading Research Quarterly, 48(2), 175-197.

Fang, Z., \& Pace, B. (2013). Teaching with challenging texts in the disciplines: text complexity and close reading. Journal of Adolescent \& Adult Literacy, 57(2), 104-108.

Fenner, D., \& Snyder, S. (2017). Unlocking English learners' potential: Strategies for making content accessible. Thousand Oaks, CA: Corwin.

Gilles, C., \& Peters, D. (2011). Extending and expanding retrospective miscue analysis. In R. Meyer \& K. Whitmore (Eds.), Reclaiming reading: Teachers, students, and researchers regaining spaces for thinking and action (pp.61-64). New York, NY: Routledge.

Glasser, B., \& Strauss, A. (1967). The discovery of grounded theory. Chicago, IL: Aldine Publishing Company.

Goodman, K. (1976). Reading: A psycholinguistic guessing game. In A. Flurkey \& J. Xu (Eds., 2003), On the revolution of reading: The selected writings of Kenneth S. Goodman (pp. 46-58). Portsmouth, NH: Heinemann.

Goodman, Y. (1996). Revaluing readers while readers revalue themselves: Retrospective miscue analysis. The Reading Teacher, 49(8), 600609.

Goodman, Y., Martens, P., \& Flurkey, A. (2014). The essential RMA: A window into readers' thinking. Katonah, NY: Richard C. Owen.

Goodman, Y., Watson, D., \& Burke, C. (2005). Reading miscue inventory: From evaluation to instruction. New York, NY: Richard C. Owen.

Huang, S. (2006). Reading English for academic purposes-What situational factors may motivate learners to read? System, 34, 371-383. 
Institute of International Education. (2016). Top 25 Places of Origin of International Students, 2014/15-2015/16. Open Doors Report on International Educational Exchange. Retrieved from http://www.iie.org/opendoors

Kim, M. (2010). Adult ESL Korean readers' responses about their reading in L1 Korean and L2 English. Unpublished doctoral dissertation. The University of Arizona. Tucson, AZ.

Koda, K. (2007). Insights into second language reading. Cambridge University Press.

Kucer, S. (2014). Dimensions of literacy: A conceptual base for teaching reading and writing in school settings (4th ed.). New York: Routledge.

Li, S., \& Munby, H. (1995). Metacognitive strategies in second language academic readings: a qualitative investigation. English for Specific Purposes, 15(3), 199-216.

Ma, W., \& Wang, C. (2014). Learner's privilege and responsibility: A critical examination of the experiences and perspectives of learners from Chinese backgrounds in the United States. Charlotte, NC: Information Age Publishing, INC.

Marek, A. T. (1987). Retrospective miscue analysis as an instructional strategy with adult readers. Unpublished doctoral dissertation. The University of Arizona. Tucson, AZ.

Martens, P., \& Doyle, M. (2011). Revaluing readers and reading: Learning from the "Mighty Readers." In R. Meyer \& K. Whitmore (Eds.), Reclaiming reading: Teachers, students, and researchers regaining spaces for thinking and action (pp. 45-60). New York, NY: Routledge.

McKenna, M., \& Robinson, R. (2014). Teaching through text: Reading and writing in the content areas. Upper Saddle River, NJ: Pearson.

Moore, R., \& Gilles, C. (2005). Reading conversations: Retrospective miscue analysis with struggling readers. Portsmouth, $\mathrm{NH}$ : Heinemann.

Moteallemi, G. (2010). ESL students' beliefs and strategies. Unpublished doctoral dissertation. The University of Alberta. Edmonton, Alberta.

Na, B., Schallert, D., \& Jee, E. (2015). When a topic matters to you, does it matter if you read about it in a second language? Literacy Research: Theory, Method, and Practice, 64, 149-168.

O'Brien, L., \& Leighton, C. (2015). Use of increasingly complex text to advance ELs' knowledge and academic language. Literacy Research: Theory, Method, and Practice, 64, 169-192. 
Paulson, E. J., \& Mason-Egan, P. (2007). Retrospective miscue analysis for struggling postsecondary readers. Journal of Developmental Education, 31(2), 2-13.

Protacio, M., \& Jang, B. (2016). ESL teachers' perceptions about English Learners' reading motivation. Literacy Research: Theory, Method, and Practice, 65, 166-181.

Rosenblatt, L. (1978). The reader, the text, the poem: The transactional theory of the literary work. Carbondale, IL: Southern Illinois University Press.

Schoenbach, R., Greenleaf, C., \& Murphy, L. (2012). Reading for understanding: How reading apprenticeship improves disciplinary learning in secondary and college classrooms (2nd ed.). San Francisco, CA: Jossey-Bass.

Shanahan, C. (2013). What does it take? The challenge of disciplinary literacy. Journal of Adolescent \& Adult Literacy, 57(2), 93-98.

Shanahan, C., \& Shanahan, T. (2014). The implications of disciplinary literacy. Journal of Adolescent \& Adult Literacy, 57(8), 628-631.

Shanahan, T., \& Shanahan, C. (2008). Teaching disciplinary literacy to adolescents: Rethinking content-area literacy. Harvard Educational Review, 78(1), 40-59.

Snow, M. A., \& Brinton, D. M. (1988). Content-based language instruction: Investigating the effectiveness of the adjunct model. TESOL Quarterly, 22, 553-574.

Su, M., \& Harrison, L. (2016). Being wholesaled: An investigation of Chinese international students' higher education experiences. Journal of International Students, 6(4), 905-919.

Yin, R. (2017). Case study research and applications (6th ed.). Thousand Oaks, CA: SAGE.

Vygotsky, L. S. (1978). Mind in society: The development of higher psychological process. Cambridge, MA \& London, England: Harvard University Press.

Wang, C., \& Zuo, H. (2014). Understanding Chinese international students' difficulties and strategies in learning English for academic purposes. In W. Ma \& C. Wang (Eds.), Learner's privilege and responsibility (pp. 67-82). Charlotte, NC: Information Age Publishing, INC.

Wang, Y. (2014). Reading in Mandarin and English: Using reading miscue inventory and retrospective miscue analysis with adult English language learners. Unpublished doctoral dissertation. University of Missouri, Columbia, MO. 
Wang, Y., \& Gilles, C. (2017). Reading in English and in Chinese: Case study of Retrospective Miscue Analysis with two adult ELs. Reading Horizons, 56(2), 64-92.

Wang, Y., \& Zheng, Y. (2019). "We help each other": Collaborative exploration of reading by college students of English as a foreign language in China. TESOL Journal, 10(1), 1-14. DOI: 10.1002/tesj.363.

Wurr, A., Theurer, J., \& Kim, K. (2009). Retrospective Miscue Analysis with proficient adult ESL readers. Journal of Adolescent \& Adult Literacy, 52(4), 324-333.

YANG WANG, PhD, is an Assistant Professor in Language and Literacy Education at the University of South Carolina. Her research focuses on reading comprehension, reading assessment, disciplinary literacy, English language teaching and learning, and biliteracy. Email: wangyang211@gmail.com 